\title{
Pelatihan Pembuatan Sabun Dengan Bahan Pewarna Ekstrak Tanaman Pada Siswa SMPIT Khairunnas Bengkulu
}

\author{
Agus MH Putranto ${ }^{1}$, Eni Widiyati*2, Teja Dwi Sutanto ${ }^{3}$ \\ ${ }^{123}$ Jurusan Kimia FMIPA Universitas Bengkulu \\ *E-mail: widiyati58@unib.ac.id
}

\section{Article History:}

Received: Desember 2020

Revised: Januari2021

Accepted: Juni 2021

Available online: Juni 2021

\section{Kata Kunci:}

sabun, pewarna, ekstrak tanaman

\begin{abstract}
Abstrak:
Kegiatan ini bertujuan untuk mengadakan pelatihan tentang pembuatan sabun dengan menggunakan pewarna ekstrak dari beberapa bagian tanaman yang berwarna, pada siswa SMPIT Khairunnas kota Bengkulu. Target khusus yang ingin dicapai adalah agar siswa SMPIT Khairunnas kota Bengkulu mampu membuat ekstrak dari bagian tanaman yang berwarna sebagai bahan pewarna dan mampu membuat sendiri sabun dengan diberi pewarna ekstrak yang telah dibuat. Untuk mencapai tujuan tersebut, maka metode yang digunakan adalah ceramah, diskusi, demonstrasi dan praktek langsung pembuatan ekstrak bagian tanaman yang berwarna dan pembuatan sabun dengan pewarna ekstrak yang telah dibuat. Diharapkan kegiatan ini dapat dipergunakan sebagai bekal pengetahuan dan ketrampilan bagi siswa SMPIT Khairunnas kota Bengkulu.
\end{abstract}




\section{Pendahuluan}

Sabun merupakan bahan yang digunakan untuk mencuci atau membersihkan kotoran, baik pada saat mandi, mencuci pakaian, mencuci piring dan membersihkan bahan-bahan kotor yang lain dan biasanya digunakan bersama-sama dengan air. Sabun dapat berfungsi sebagai pembersih karena mengandung dua gugus yang memiliki sifat berbeda yaitu gugus hidrofil (- $\left.\mathrm{COO}^{-}\right)$yang dapat berantaraksi dengan air dan gugus hidrofob (R-) yang dapat berantaraksi dengan minyak atau lemak. Sabun dapat dibuat dari hasil reaksi antara minyak/lemak dengan suatu basa .Salah satu minyak yang dapat digunakan untuk membuat sabun adalah Virgin Coconut Oil (VCO) atau yang dikenal dengan minyak kelapa virgin. Minyak ini merupakan minyak yang diperoleh dari daging buah kelapa, menggunakan metode tanpa pemanasan, sehingga akan dihasilkan minyak yang tidak berwarna (jernih), tidak mudah tengik, dan tahan bertahun-tahun jika disimpan. VCO mengandung 93\% asam lemak jenuh (Alvarez dan Rodriques, 2000), sehingga cocok untuk pembuatan kosmetik. Sebagian besar dari asam lemak jenuh tersebut berupa asam lemak rantai sedang (medium chain fatty acids =MCFAs), yang menyebabkan minyak ini mudah dicerna oleh tubuh. Sebanyak 47-50\% dari MCFA berupa asam laurat (Kamariah dkk., 2008), yang jika dikonsumsi, maka asam laurat ini di dalam tubuh manusia akan diubah menjadi monolaurin yang berfungsi sebagai antivirus, antibakteri dan antiprotozoa (Rubin, 2003).

Saat ini, sabun termasuk ke dalam bahan kebutuhan pokok karena hampir setiap hari bahan ini dibutuhkan oleh masyarakat. Di pasaran dikenal berbagai bentuk sabun seperti sabun padat dan sabun cair. Untuk lebih menarik perhatian pembeli maka saat ini banyak dijumpai sabun dengan aneka warna yang berbeda dan juga dengan aroma yang berbeda-beda pula. Oleh karena sabun digunakan pada permukaan kulit, maka sebagai pewarna perlu dipilih bahan yang aman sehingga tidak membahayakan kulit. Salah satu contoh pewarna yang dapat digunakan adalah pewarna dari sumber alam hayati yaitu ekstrak bagian tanaman yang berwarna, seperti warna hijau dapat diperoleh dari daun pandan, daun suji. Warna kuning dapat diperoleh dari kunyit dan warna jingga dapat dihasilkan dari wortel. 
Di Pasaran, saat ini sudah banyak tersedia sabun mandi dengan berbagai merk dan beraneka warna, yang dijual di toko-toko, atau di warungwarung, namun belum banyak masyarakat, termasuk sebagian siswa SMPIT Khairunnas Bengkulu, yang belum mengetahui bahan-bahan apa saja yang dipergunakan untuk membuat sabun. Masyarakat belum banyak yang mengetahui bagaimana cara pembuatan sabun, pembuatan pewarna alami, dan bagaimana cara memberi warna sabun. Untuk itu pelatihan pembuatan ekstrak zat warna dari beberapa bagian tanaman yang berwarna, pembuatan sabun mandi dengan pewarna ekstrak bagian tanaman pada siswa SMPIT Khairunnas Bengkulu perlu dilakukan. Diharapkan kegiatan ini dapat dipergunakan sebagai bekal pengetahuan dan ketrampilan bagi siswa SMPIT Khairunnas, Bengkulu.

\section{Metode}

Kegiatan ini diawali dengan ceramah untuk menjelaskan kepada siswa SMPIT Khairunnas Bengkulu tentang cara pembuatan ekstrak bagian tanaman yang berwarna, cara pembuatan sabun yang diberi warna dan manfaat yang diperoleh dari kegiatan ini. Juga dijelaskan manfaat dari sabun yang akan dibuat.

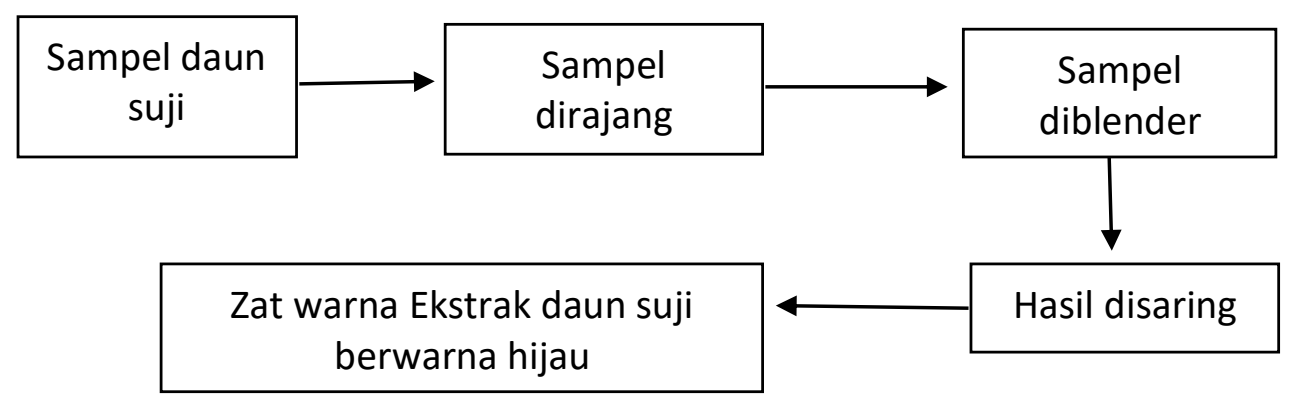

Gambar 1. Langkah kerja pembuatan zat warna ekstrak tanaman yang berwarna (contoh pembuatan pewarna ekstrak daun suji)

Selanjutnya diberikan kesempatan kepada para siswa untuk mengajukan pertanyaan dan berdiskusi tentang pembuatan sabun dengan pewarna ekstrak bagian tanaman. 
Kegiatan selanjutnya adalah dilakukan demonstrasi tentang pembuatan ekstrak dari bagian tanaman yang berwarna seperti daun suji, wortel dan kunyit. Kemudian para siswa diberi kesempatan untuk praktek langsung membuat ekstrak zat warna dari bagian tanaman yang berwarna dan praktek membuat sabundengan diberi bahan pewarna ekstrak bagian tanaman yang berwarna. Adapun langkah kerja yang dilakukan pada pembuatan ekstrak bagian tanaman disajikan di Gambar 1. Dengan cara yang sama dibuat juga ekstrak wortel dan kunyit sebagai bahan zar warna.

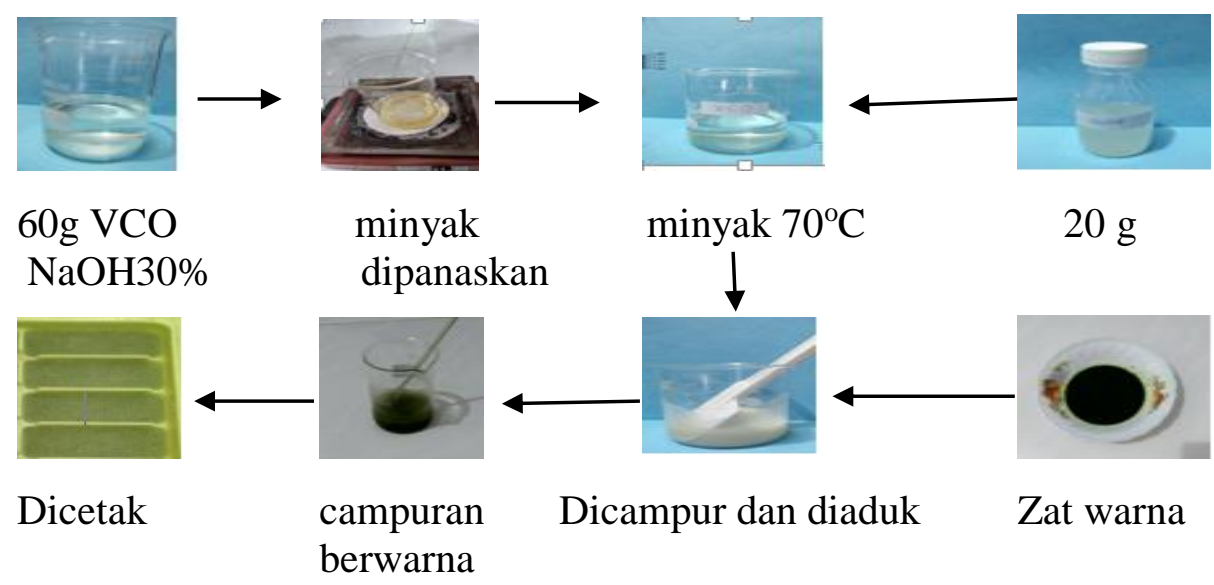

Gambar 2. Langkah kerja pembuatan sabun dengan pewarna ekstrak bahan alam hayati

Langkah selanjutnya adalah pembuatan sabun dengan pewarna ekstrak tanaman. Pada kegiatan ini telah dipraktekkan pembuatan sabun yang diberi warna dengan ekstrak bahan alam nabati dengan langkah kerja seperti disajikan pada Gambar 2. Kegiatan ini diakhiri dengan melakukan evaluasi yang berhubungan dengan pembuatan ekstrak zat warna dan pembuatan sabun dengan pewarna ekstrak bahan alam hayati untuk mengetahui keberhasilan dari kegiatan ini.

\section{Hasil}

Pada kegiatan ini telah dibuat 3 macam zar warna ekstrak bagian tanaman yaitu zat warna hijau dari daun suji, zat warna orange dari wortel dan zat warna kuning dari kunyit (Gambar 3). Zat warna alami yang dihasilkan 
digunakan untuk mewarnai sabun yang dibuat.

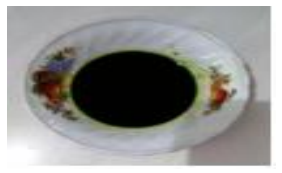

A



B

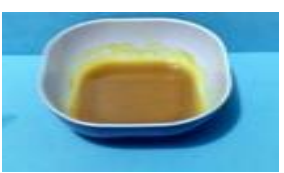

C

Gambar 3. Foto zat warna ekstrak bagian tanaman A. daun suji, B. wortel, C. kunyit

Pada kegiatan ini telah dihasilkan 3 sabun dengan warna yang berbeda yaitu hijau, kuning dan orange (Gambar 4).

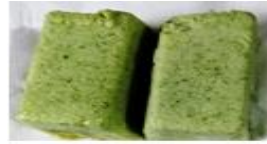

1

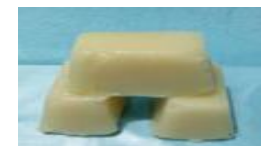

2

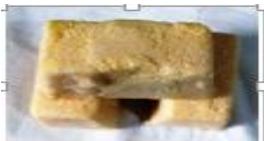

3

Gambar 4. Foto sabun berwarna 1. hijau (ekstrak daun suji), 2. Kuning (ekstrak kunyit), 3. Orange (ekstrak wortel)

Para siswa SMPIT Khairunnas terlihat sangat antusias mengikuti seluruh kegiatan ini mulai dari penjelasan secara ceramah, tanya jawab, demonstrasi hingga praktek pembuatan zat warna ekstrak bahan alam hayati. Hal ini terlihat dari banyaknya peserta yang hadir dan ikut praktek membuat zat warna tersebut. Gambar 5. Menyajikan foto keterlibatan siswa SMIPIT Khairunas membuat ekstrak dan sabun.


Gambar 5. Foto para siswa praktek membuat ekstrak zat warna dan sabun yang diberi pewarna ekstrak bahan alam hayati

Pada kegiatan ini juga telah diperoleh hasil evaluasi dari para siswa SMPIT Khairunas terhadap kegiatan yang telah dilakukan. Dari hasil evaluasi dapat diketahui bahwa sebanyak $79 \%$ siswa sudah mengetahui cara membuat ekstrak bahan alam hayati. Sebanyak $70 \%$ siswa sudah mengetahui cara 
pembuatan sabun. Sebanyak $91 \%$ dari peserta pelatihan menyatakan bahwa materi yang disampaikan pada pelatihan ini menarik dan sebanyak $79 \%$ peserta pelatihan menyatakan cara penyampaian materi pelatihan ini menarik. Sebanyak $82 \%$ siswa menyatakan bahwa petunjuk cara pembuatan zat warna ekstrak dari bahan alam hayati yang terdapat dalam naskah power point mudah dipahami. Demikian juga dengan pedoman pembuatan sabun dengan pewarna ekstrak bahan alam hayati yang disajikan di dalam naskah power point juga mudah dipahami oleh sebanyak $88 \%$ peserta pelatihan.

Sebanyak 94\% dari peserta menyatakan bahwa pelatihan pembuatan ekstrak zat warna alam hayati ini sangat bermanfaat bagi peserta. Sebanyak $70 \%$ siswa SMPIT Khairunnas Bengkulu yang mengikuti pelatihan ini menyatakan bahwa pelatihan pembuatan sabun dengan pewarna alami bermanfaat. Sebanyak $88 \%$ sudah mengetahui cara pembuatan ekstrak dari bahan alam hayati. Sebanyak $85 \%$ peserta paham cara pembuatan sabun dengan pewarna bahan alam hayati.

\section{Diskusi}

Dari kegiatan pelatihan yang telah dilakukan, maka dapat diketahui bahwa sebagian besar siswa sudah mengetahui cara membuat ekstrak bahan alam hayati, mengingat cara pembuatannya memang sangat mudah, yaitu hanya dengan cara seperti membuat jus buah-buahan, jadi tidak asing bagi para siswa peserta pelatihan. Sebagian besar siswa sudah mengetahui cara pembuatan sabun, karena memang pada tahun 2018 pernah dilakukan pelatihan pembuatan sabun, namun belum diberi pewarna.

Pada pelaksanaan kegiatan pengabdian ini dibagikan pedoman cara pembuatan ekstrak dan pembuatan sabun dengan pewarna ekstrak bahan alam hayati kepada masing-masing peserta. Diharapkan pedoman tersebut dapat dipergunakan sebagai acuan pada pembuatan zat warna dan sabun. Dari hasil evaluasi dapat diketahui bahwa hampir seluruh peserta pelatihan menyatakan bahwa materi dan cara penyampaian materi pada pelatihan ini menarik. Hal ini menunjukkan bahwa kegiatan pelatihan pembuatan zat warna berupa ekstrak dari bahan alam dan pembuatan sabun dapat menarik perhatian para siswa peserta pelatihan. 
Hasil evaluasi menunjukkan petunjuk cara pembuatan zat warna ekstrak dari bahan alam hayati yang terdapat dalam naskah power point mudah dipahami. Demikian juga dengan pedoman pembuatan sabun dengan pewarna ekstrak bahan alam hayati yang disajikan di dalam naskah power point juga mudah dipahami. Diharapkan dengan mudah dipahami oleh peserta, maka para siswa akan lebih mudah untuk mempraktekkan pembuatan sabun dengan pewarna ekstrak bahan alam, dengan menggunakan pedoman yang telah dibagikan. Sebagian besar peserta menyatakan bahwa pelatihan pembuatan ekstrak zat warna alam hayati ini sangat bermanfaat, demikian juga dengan pelatihan pembuatan sabun dengan pewarna alami. Dengan dilaksanakannya pelatihan ini diharapkan dapat para siswa memiliki bekal pengetahuan dan ketrampilan, sehingga diharapkan dapat dipergunakan sebagai bekal di masa mendatang, mengingat pembuatan zat warna dengan cara mengekstrak bahan alam hayati seperti wortel, kunyit, daun suji memang mudah dilakukan, karena hanya menggunakan pelarut air, seperti membuat jus dari buah-buahan, sudah dapat diperoleh bahan pewarna alami, yang aman dan ramah lingkungan.

Dengan memiliki pengetahuan tentang cara pembuatan sabun, maka diharapkan juga ketrampilan ini dapat dipergunakan sebagai bekal pengetahuan untuk studi lanjut. Atau kelak apabila sudah dewasa berkeinginan untuk berwira usaha di bidang pembuatan sabun, sehingga akan membuka lapangan pekerjaan dan dapat menghasilkan uang. Mengingat sabun adalah bahan kebutuhan sehari-hari, maka produk ini akan selalu dipergunakan dalam kehidupan sehari-hari, seperti untuk mandi, mencuci baju, mencuci pakaian. Sabun yang dipergunakan dalam kehidupan sehari-hari dapat dibuat dari hasil reaksi antara minyak salah satunya adalah $\mathrm{VCO}$ dengan $\mathrm{NaOH}$ (merupakan suatu basa). Untuk meningkatkan daya tarik dan nilai jual maka dapat ditambahkan pewarna dan pengharum. Dapat juga ditambahkan bahan aktif tertentu, sehingga dapat dipergunakan sebagai obat.

Dengan memperhatikan hasil evaluasi dari peserta pelatihan, maka dapat diambil kesimpulan bahwa pelatihan pembuatan sabun dengan pewarna ekstrak bahan alam hayati pada siswa SMPIT Khairunnas Bengkulu telah berhasil dilakukan. Para siswa dapat mengambil manfaat dari pelatihan ini dan diharapkan dapat digunakan sebagai bekal pengetahuan dan ketrampilan di masa mendatang. 


\section{Kesimpulan}

Berdasarkan hasil pelaksanaan kegiatan pengabdian pada masyarakat berupa pelatihan pembuatan sabun dengan pewarna ekstrak bahan alam hayati, maka dapat dibuat kesimpulan bahwa kegiatan pengabdian kepada masyarakat tentang pelatihan pembuatan sabun dengan pewarna ekstrak bahan alam hayati pada siswa SMPIT Khairunnas Bengkulu telah berhasil dilakukan. Sebagian besar siswa SMPIT Khairunnas Bengkulu menyatakan bahwa kegiatan ini sangat bermanfaat dan sebagian besar dari mereka telah mengetahui cara pembuatan ekstrak bahan alam hayati sebagai bahan pewarna.Sebagian besar siswa SMPIT Khairunnas Bengkulu telah mengetahui cara pembuatan sabun dengan pewarna ekstrak bahan alam hayati.

\section{Pengakuan/Acknowledgements}

Penulis mengucapkan terima kasih kepada Dekan FMIPA, Universitas Bengkulu yang telah memberikan sebagian dana RBA FMIPA tahun 2019 (No kontrak1887/UN30.12/HK/2019), sehingga kegiatan Pengabdian Pada Masyarakat (PPM) dengan judul "Pelatihan pembuatan sabun dengan pewarna ekstrak bahan alam hayati pada siswa SMPIT Khairunnas Bengkulu” ini dapat terlaksana.

\section{Daftar Referensi}

Alvarez, A. M. R., and Rodriquez, M. L. GLipids in Pharmaceutical and Cosmetic Preparations, Grasas. Aceites, 51, 2000, 74-96.

Gediya, S. K., Mistry, R. B., Patel, U. K., Blessy, M. and Jain, H. N., Herbal Plants : Used as a Cosmetics, J. Nat. Plant Resour., 1 (1), 2011, 2432.

Febriyenti; Lisa Indah Sari; Rahmi Nofita. 2014. Formulasi Sabun Transparan Mintak Ylang-Ylang dan Uji Efektivitasterhadap Bakteri Penyebab Jerawat.

Jurnal Sains Farmasi dan Klinis Universitas Andalas, Padang. Hal. 63.

Kamariah, L., Azim, A., Rosmawati, A., Ching, M.G.W., Azlina, M.D.,

Sivapragasam, A., Tan, C.P., dan Lai, O.M., Physico-chemical and Quality Characteristics of Virgin Coconut Oil-A Malaysian Survey, J. Trop. Agric. and Fd. Sc., 36 (2), 2008,1-10.

Krishna, G. A. G., Raj, G., Bhatnagar, A., S., Kumar, P. P. K., and Chandrashekar, P., Coconut Oil : Chemistry, Production and Its 
Applications- a Review, Indian Coconut J., 2010, 15-27.

Lu H. F. S. and Tan, P. P. , A Comparative Study of Storage Stability in VCO and Extra Virgin Olive Oil, Upon Thermal Treatment, Int. Food Res. J. 16, 2009, 343-354.

Pratap, A. P., Value Added Products from Coconut Oil, J. Cocoinfo Int. , 16 (2), 2009, 24-32.

Rubin, J., Extra Virgin Coconut Oil-the Good Saturated Fat, Total Health, 25 (3), 2003, 30.

Setiaji, B., Menyingkap keajaiban minyak kelapa virgin, Pusat Pengolahan Kelapa Terpadu, Yogyakarta, 2005.

Setiaji, B. dan Prayugo, S., Membuat VCO Berkualitas Tinggi, Penebar Swadaya, Jakarta, 2006 